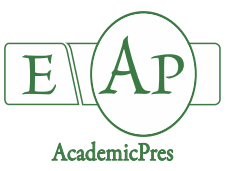

Wang T et al. (2021)

Notulae Botanicae Horti Agrobotanici Cluj-Napoca

Volume 49, Issue 3, Article number 12407

DOI: $10.15835 /$ nbha 49312407

Research Article

\title{
Association between spatial genetic variation and potential distribution in tree fern Alsophila gigantea (Cyatheaceae) in Hainan Island, China
}

\author{
Ting WANG ${ }^{1}$, Zhen WANG ${ }^{2}$, Shufeng $\mathrm{LI}^{2}$, Zhanming YING ${ }^{2,3}$, \\ Xiaoxian RUAN ${ }^{2}$, Yingjuan $\mathrm{SU}^{2,4 *}$
}

\author{
${ }^{1}$ South China Agricultural University, College of Life Sciences, Guangzhou, China; tingwang@scau.edu.cn \\ ${ }^{2}$ Sun Yat-sen University, School of Life Sciences, Guangzhou, China; 1257110928@qq.com; ssuzzi@qq.com; \\ zmying@xtu.edu.cn; ruanxx@mail2.sysu.edu.cn; suyj@mail.sysu.edu.cn (*corresponding author) \\ ${ }^{3}$ Xiangtan University, College of Chemistry, Xiangtan, China; \\ ${ }^{4}$ Research Institute of Sun Yat-sen University in Shenzhen, Shenzhen, China
}

\begin{abstract}
Spatial genetic variation involves spatial genetic structure (SGS) and genetic diversity is important genetic features of plants. We first evaluated spatial genetic structure (SGS) and genetic diversity among four populations of Alsophila gigantea from Hainan Island, China, using inter-simple sequence repeat (ISSR) markers. Significant but weak FSGS was found in $A$. gigantea. High genetic diversity was identified at the species level and the population level. AMOVA analysis revealed a low level of genetic differentiation among the four populations with high gene flow. Mantel test showed no significant correlation between genetic distance and geographic distance. It was found that association between annual mean temperature and annual precipitation with FSGS. Combined with these spatial genetic variation, abundant precipitation and suitable temperature create a stable environment for $A$. gigantea in Hainan Island, which allows the fern to expand rapidly during the LGM. These results further emphasized the role of outcrossing, and history and environmental factors in the evolution of $A$. gigantea. This study also provided new insights on in local adaptation of $A$. gigantea to environmental fluctuations, and available genetic data to enhance the conservation for relict tree ferns.
\end{abstract}

Keywords: Alsophila gigantea; environmental factors; genetic diversity; Hainan Island; ISSR; potential distribution; spatial genetic structure; tree ferns

\section{Introduction}

Spatial genetic variation includes spatial genetic structure (SGS) and genetic diversity, which are two important genetic features of plants. The former is referred to non-random distribution of individual genotypes in natural populations (Ramírez-Barahona and Eguiarte, 2015), while the latter is raw materials for against disease and adaptation to changing environment. The both genetic indices are affected by the similar factors including dispersal ability, mating system, life form, population density, human disturbance as well as historical events (Vekemans and Hardy, 2004; Chung and Chung, 2013; González-Díaz et al., 2017). Among them, gene flow related to dispersal plays an important role (Troupin et al., 2006). In addition, fine spatial genetic structure

Received: 20 Jun 2021. Received in revised form: 20 Aug 2021. Accepted: 13 Sep 2021. Published online: 23 Sep 2021.

From Volume 49, Issue 1, 2021, Notulae Botanicae Horti Agrobotanici Cluj-Napoca journal uses article numbers in place of the traditional method of continuous pagination through the volume. The journal will continue to appear quarterly, as before, with four annual numbers. 
is also affected by environmental heterogeneity such as altitudinal, temperatures, and precipitation compared to genetic diversity (Troupin et al., 2006; Torroba-Balmori et al., 2017; Mosca et al., 2018).

Gene flow is mainly from dispersal of pollen, seed, spore and propagule (Wang and Bradburd, 2014). For ferns, gene flow is closely related to a large number of tiny $(0.029-0.031 \mathrm{~mm})$ and wind-borne spores and unique mode of reproduction involving in independent haploid and diploid phase (Wang et al., 2012; Bucharová and Münzbergová, 2012). Long distance spore dispersal can homogenize the differentiation among populations, reduce spatial genetic differentiation, and increase genetic diversity, which are further deepened in outcrossing rather than inbreeding ferns (Pryor et al., 2001; Jiménez et al., 2010; Wang et al., 2012; Sessa et al., 2016). However, it is unclear whether this hypothesis is acceptable for ferns in Hainan Island with several main mountains similar to "island within island", which greatly affects gene flow in the spatial scale (Saro et al., 2019).

Hainan Island is the second largest island in China with abound ferns, which is isolated from mainland by Qiongzhou Strait with connection-disconnection events. It provides a very suitable island framework to address issues about pattern of spatial genetic structure (SGS) and genetic diversity. The island comprises diverse famous mountains far apart such as Jianfengling, Bawangling, Diaoluoshan, and Wuzhishan, which look like "independent islands" with spatio-temporal isolation within Hainan Island (Saro et al., 2019). In general, island populations have low genetic variation due to colonization events, founder effects, finite population size, and adaptations to island environments (Frankham, 1997; Su et al., 2010). The isolated spatial distribution of island populations further affects proportion of genetic variation among the populations (Nielsen, 2004). Due to high gene flow and complicated breeding systems, genetic features of ferns are generally contrary to these conclusions (Soltis et al., 1991; Sessa et al., 2016), with limited researches in Pteris multifida, Dryopteris aemula, Cyrtomium falcatum, and Alsophila firma (Murakami et al., 1997; Jiménez et al., 2010; Chung et al., 2013; Ramírez-Barahona and Eguiarte, 2015). Ferns are key component of Hainan Island flora and play important roles in ecosystem (Dong, 2009). Especially, tree ferns represent a significant characteristic for rain forest of tropical and subtropical climate (Paul et al., 2015). However, their survival crisis is attributed to the lack of effective gene flow between the fragmented small populations (Wang et al., 2003). Hence, it is necessary to further investigate SGS and genetic diversity of tree ferns driven by gene flow in Hainan Island.

Suitable habitat is crucial for the survival and growth of ferns, especially in conservation biology of endangered ferns (Li et al., 2019; Manel et al., 2001). Climate has directly or indirectly great significance on distribution including suitable habitat, identification of which contribute to mitigate negative effects of climate fluctuation in global climate change. The heterogeneity of precipitation and temperature exerts great pressure to growth and reproduction of ferns, especially in island regions. The impact consequences and determinative factors can be determined by ecological niche modelling, which has been widely used in accurate distribution predictions of species (Zhang et al., 2021). Combined with spatial genetic variation and biological characteristics of species, we can obtain distinct understanding to distribution of ferns in past, present, and future.

Alsophila gigantea is an important relict tree fern of family Cyatheaceae. As a giant fern, its erect stem is tall up to 2-5 meter with huge foliage. Fronds are bi or tripinnate with 2-3 m length. The stipe has dark brown and glossy scales (Wang et al., 2019). The fern prefers to grow in moist open areas in dense forests at an altitude up to $1200 \mathrm{~m}$ in China including Hainan Island and other southeast Asian countries (Zhang and Nishida, 2013). As an ornamental and medicinal fern, it is regarded as a vulnerable species (Fu, 1992) and included in Appendix II of CITES (2017) due to illegal collection, human disturbance, and severe deforestation (Au, 2004; Ibars and Estrelles, 2012). Haploid spores are the main breeding way of A. gigantea with strict temperature requirement in storage, germination, development, and fertilization (Conant, 1990; Soltis et al., 1990; 1991; Li et al., 2010; Cao et al., 2007; Du, 2009), which is a huge challenge for its conservation. In Hainan Island, $A$. gigantea mainly distributes in Jianfengling, Bawangling, Diaoluoshan, and Wuzhishan as isolated "island populations". It is suitable to investigate SGS mode and genetic variation, and related effect factors. 
In this study, we adopted ISSR molecular markers and simultaneously combined multivariate statistics and spatial genetic autocorrelation analysis to survey SGS and genetic diversity of $A$. gigantea (Kalisz et al., 2001; Vekemans and Hardy, 2004). Our goals are to present pattern of SGS and genetic diversity for $A$. gigantea in Hainan Island, and explore which environmental factors have exerted important effects on its SGS and genetic diversity.

\section{Materials and Methods}

\section{Study region and species}

We sampled 223 individuals from four populations of $A$. gigantea in Hainan Island (Figure 1), which were located in Diaoluoshan (DL, N=33; $425-470 \mathrm{~m}$ elevation), Wuzhishan (WZ, N=33; 705-785 m elevation), Jianfengling (JF, $\mathrm{N}=28$; 806-926 m elevation) and Bawangling (BW, $\mathrm{N}=23$; 919-1024 m elevation), respectively. Fresh and young leaves were collected and preserved in Ziplock plastic bags with silica gel immediately until extraction.

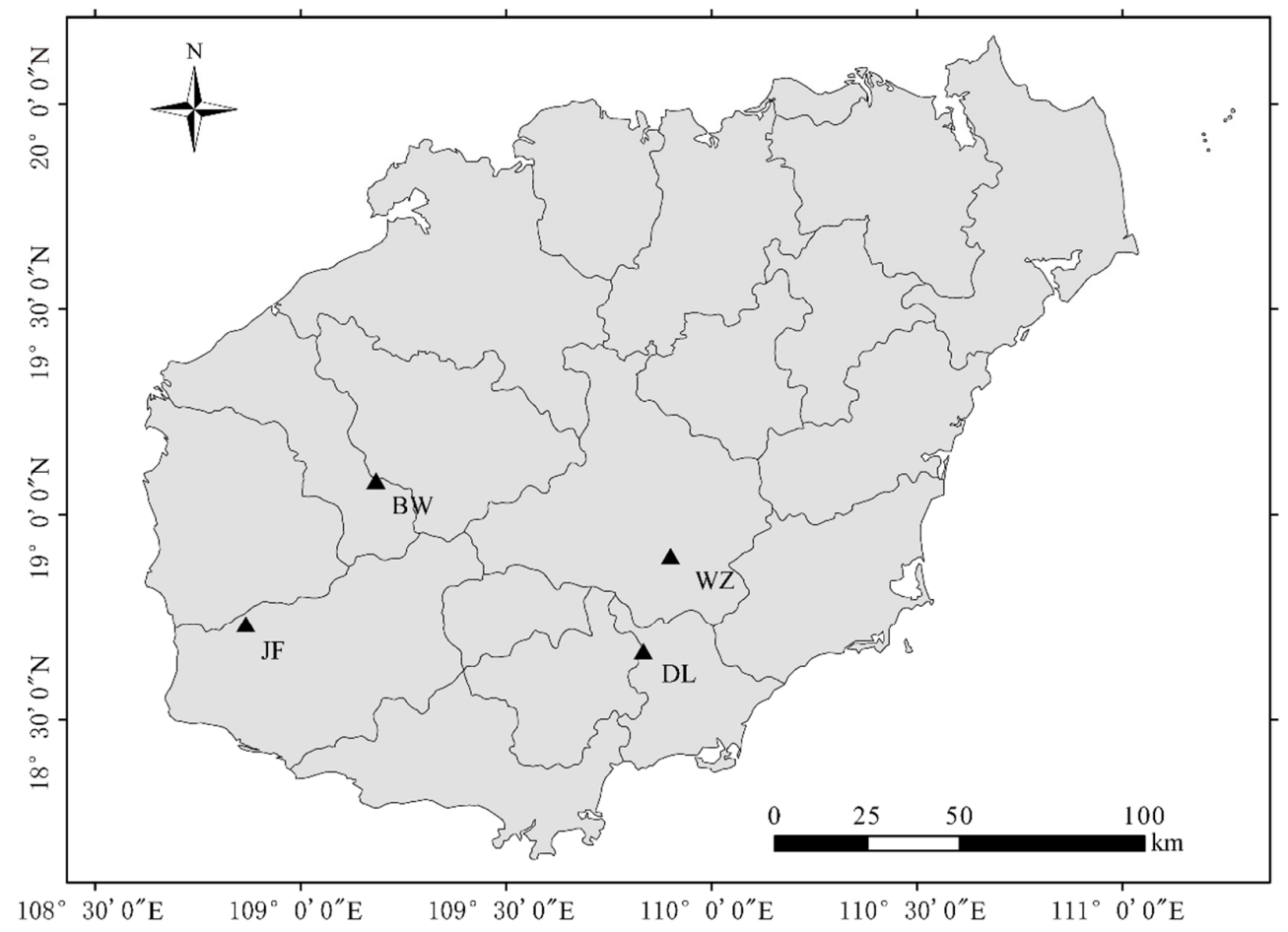

Figure 1. Geographic distribution of the four population of $A$. gigantea in Hainan, China DL: Diaoluoshan; WZ: Wuzhishan; JF: Jianfengling; BW: Bawangling.

\section{DNA extraction and ISSR amplification}

A modified cetyltrimethyl ammonium bromide (CTAB) method was used to isolates genomic DNA, which was stored at $-20^{\circ} \mathrm{C}$ until subsequent use (Su et al., 1998). We screened out 23 primers from UBC ISSR Primers 801-900 (the Biotechnology Laboratory, University of British Columbia) (Table 1). PCR amplification reaction was performed in $20 \mu \mathrm{L}$ volume, including $2.0 \mu \mathrm{L} 10 \times$ buffer, $1.5 \mu \mathrm{L} 20 \mathrm{mM}$ of $\mathrm{MgCl}_{2}$, $0.4 \mu \mathrm{L} 10 \mathrm{mM}$ of $\mathrm{dNTP}, 0.3 \mu \mathrm{L} 0.011 \mathrm{mM}$ of each primer, $1 \mathrm{U}$ of Taq polymerase and $50 \mathrm{ng}$ DNA. Amplification procedures were as follows: an initial denaturation at $94^{\circ} \mathrm{C}$ for $5 \mathrm{~min}$, followed by 40 cycles of 40s at $94^{\circ} \mathrm{C}$, 35 s at $53^{\circ} \mathrm{C}$ and 70 s at $72^{\circ} \mathrm{C}$ before final elongation at $72^{\circ} \mathrm{C}$ for $5 \mathrm{~min}$. The amplified products 
were electrophored using $1.8 \%$ agarose gel with 100 bp DNA ladder, which was stained with Ethidium Bromide and visualized using $254 \mathrm{~nm}$ ultraviolet lamp.

Table 1. Primer sequences used in the study

\begin{tabular}{|c|c|c|c|}
\hline Primer number & Primer sequences 5' - 3' & Primer number & Primer sequences 5' - 3' \\
\hline UBC814 & СТС ТСТ СТС ТСТ СТС ТА & UBC815 & СТС ТСТ СТС ТСТ СТC TG \\
\hline UBC818 & CAC ACA CAC ACA CAC AG & UBC825 & ACA CAC ACA CAC ACA CT \\
\hline UBC820 & GTG TGT GTG TGT GTG TC & UBC827 & ACA CAC ACA CAC ACA CG \\
\hline UBC824 & TCT СТC ТСТ СТС ТCT CG & UBC841 & GAGAGAGAGAGA GAG AYC \\
\hline UBC844 & CTC TCT CTC TCT CTC TRC & UBC845 & CTC TCT CTC TCT CTC TRG \\
\hline UBC846 & CAC ACA CAC ACA CAC ART & UBC849 & GTG TGT GTG TGT GTG TYA \\
\hline UBC 850 & GTG TGT GTG TGT GTG TYC & UBC 851 & GTG TGT GTG TGT GTG TYG \\
\hline $\mathrm{UBC} 852$ & TCT CTC TCT CTC TCT CRA & UBC857 & ACACACACA CAC ACA CYG \\
\hline UBC854 & TCT CTC TCT CTC TCT CRG & UBC859 & TGT GTG TGT GTG TGT GRC \\
\hline UBC860* & TGT GTG TGT GTG TGT GRA & $\mathrm{UBC}^{2} 73^{*}$ & GAC AGA CAG ACA GAC A \\
\hline UBC864* & ATG ATG ATG ATG ATG ATG & UBC874* & ССС ТСС СТС ССТ ССС Т \\
\hline UBC880* & GGA GAG GAG AGG AGA & & \\
\hline
\end{tabular}

$\mathrm{R}=(\mathrm{A}, \mathrm{G}), \mathrm{Y}=(\mathrm{C}, \mathrm{T}), \mathrm{D}=(\mathrm{A}, \mathrm{G}, \mathrm{T})$ (i.e. not $\mathrm{C}), \mathrm{H}=(\mathrm{A}, \mathrm{C}, \mathrm{T})$ (i.e. not $\mathrm{G}), \mathrm{V}=(\mathrm{A}, \mathrm{C}, \mathrm{G})$ (i.e. not $\mathrm{T}$ )

Data analyses

We adopted GENALEX v.6.41 software (Peakall and Smouse, 2006) to estimate genetic parameters, including the actual number of alleles $(\mathrm{Na})$, the effective number of alleles $(\mathrm{Ne})$, Shannon's information index (I), expected heterozygosity $(\mathrm{He})$, unbiased expected heterozygosity $(\mathrm{UHe})$ and percentage of polymorphic loci (PPL). Gene flow was calculated based on Nei's genetic identity (Inei) and genetic distance (D) in pairwise population using POPGENE v.1.31 (Yeh et al., 1999). Isolation by distance (IBD) was further assessed using Mantel test (Miller, 1997) implemented in Arlequin v.3.5 (Excoffier and Lischer, 2010).

To investigate the population genetic structure, an individual-based Bayesian cluster analysis was conducted using STRUCTURE v.2.2 (Evanno et al., 2005). We set the number of clusters as $\mathrm{K}=1-7$, and adopted other following parameters: admixture model, correlated allele frequencies, burn-in period of 10000 , Markov chain Monte Carlo (MCMC) repetitions of 100 000, and 10 iterations of $\mathrm{K}$ values. The optimal $\mathrm{K}$ number was determined by the maximum value of $\Delta K$ statistic based on $\operatorname{LnP}(\mathrm{D})$, which was performed in STRUCTURE HARVESTER (http://taylor0.biology.ucla.edu/structureHarvester/) (Earl and vonHoldt, 2012). For each optimal $\mathrm{K}$ model, the probabilities that each individual was assigned to the most likely clusters were averaged over replicate chains in CLUMPP Version 1.1.2 (Jakobsson and Rosenberg, 2007), and finally visualized in DISTRUCT (Rosenberg, 2010).

Based on the optimal K number, we used Arlequin v.3.5 to further evaluate genetic differentiation and variation among populations through analysis of molecular variance (AMOVA) with 10000 permutations (Excoffier and Lischer, 2010). In addition, genetic differentiation was also estimated based on $\theta$ II, a statistical value analogous to Fst, using HICKORY v.1.1 (Holsinger et al., 2002). An optimizing model was determined by the smaller DIC from four models, which was obtained with the default parameters (burn in $=5000$, sample $=100000$, thin $=20$ ). If the difference of DIC among four models was less 5 or 6 units, the model with smaller value of the sum of Dbar (model fit) and $\mathrm{pD}$ (model complexity) had priority of adoption. HICKORY was run three times for each analysis to ensure consistency.

Based on squared allele frequency correlation coefficient $\left(\mathrm{r}^{2}\right)$ and statistical tests $(\mathrm{p})$, linkage disequilibrium (LD) was assessed using TASSEL v.3.0.169 (Bradbury et al., 2007), which was finally identified under the value of $\mathrm{r}^{2}$ less than 0.1 . 


\section{Spatial genetic structure analysis}

Based on Shannon's information index, spatial autocorrelation was evaluated using SAM v.4.0 software (Rangel et al., 2010). According to the maximum geographical distance among four populations, Moran's I statistics were calculated at four distance classes with intervals $1-30 \mathrm{~km}, 30-60 \mathrm{~km}, 60-90 \mathrm{~km}$, and $90-120 \mathrm{~km}$. The range of Moran's I is from -1 to 1 , which indicates the complete discrete and correlation, respectively. Among them, 0 indicates the random distribution. Finally, 9999 random permutations were performed to obtain confidence interval, 95\% of which determined significance of Moran's I with p-value.

Fine spatial genetic structure (FSGS) was further assessed using SPAGeDi v.1.3 (Hardy and Vekemans, 2002). To acquire more accurate results, we performed FSGS analysis among four population and four group, of which the latter was random combination of three of four populations (group1: DL+WZ+JF; group2: $\mathrm{WZ}+\mathrm{BW}+\mathrm{JF}$; group3: $\mathrm{DL}+\mathrm{BW}+\mathrm{JF}$; group4: $\mathrm{DL}+\mathrm{WZ}+\mathrm{BW})$. Within six distance intervals, kinship coefficients between every pair of individuals i and j were estimated (Fij, Loiselle et al., 1995). Based on the requirements of software for distance interval: \% partic $>50 \%$, and CV partic $<=1$, six distance intervals with $200 \mathrm{~m}$ were set within the maximum distance of $1200 \mathrm{~m}$ among four populations. Similarly, for group 1 and group 2, we set six distance intervals with $150 \mathrm{~m}$ and $170 \mathrm{~m}$ within the maximum distance of $900 \mathrm{~m}$ and 1020 $\mathrm{m}$ for group 4 and group 3 , respectively. The kinship coefficients were further regressed on geographic distance between individuals and its natural logarithm ( $\mathrm{dij}$ and $\ln (\mathrm{dij})$ to exhibit bd and bLd slopes, respectively. To obtain 95\% confidence intervals, 10000 permutations were performed. The statistic $\mathrm{Sp}$ was calculated to provide strength of FSGS using the formula $\mathrm{Sp}=-\mathrm{bLd} /(1-\mathrm{F} 1)$, where $\mathrm{F} 1$ is the mean Fij of the first distance interval. The significance of FSGS was statistically determined by p-value and $95 \%$ confidence intervals.

\section{Effects of environmental factors on genetic diversity and FSGS}

In this study, environmental factors included three geographical variables (longitude, latitude, and altitude) and 19 climatic variables. The 19 factors were downloaded from WorldClim version 2 (www.worldclim.org) for the years 1950-2000 with a 2.5 minutes spatial resolution. We used ArcGis v.10.2 to extract climatic variables of four $A$. gigantea populations. Based on Pearson correlation coefficient, SPSS v.18.0.0 was used to evaluate correlation of 21 environmental factors and six genetic parameters ( $\mathrm{Na}, \mathrm{Ne}, \mathrm{I}, \mathrm{He}$, $\mathrm{UHe}$, and PPL).

We selected annual mean temperature (bio1) and annual precipitation (bio12) as target variables to analyze the effects of climatic factors on FSGS in four groups of $A$. gigantea. Linear regression model was used to investigate relationship between temperature/precipitation variables with $S p$ value of FSGS. The two climatic data were first converted into a standardized model using "vegan" package in R. Step by step regression by backward selection method was performed in R using the step () function in "mass" package (Venables and Ripley, 2002). The optimal model was determined based on the lowest Akaike Information Criterion (AIC) value.

\section{Prediction of the potential distribution}

Geographical distribution information of $A$. gigantea was collected from Global Biodiversity Information Facility (GBIF, https://www.gbif.org/) and China Virtue Herbarium (CVH, http://www.cvh.ac.cn/). All climatic data were obtained from WorldClim (www.worldclim.org). Except current and future climatic data, we also collected paleoclimatic data, including the Holocene (HOL), the Last Interglacial (LIG; 130-115 ka BP), and the Last Glacial Maximum (LGM, 25-17 ka BP). Two different global climate models were adopted: CCSM (Community Climate System Model) (Collins et al., 2006) and MIROC (Model for Interdisciplinary Research on Climate) (Hasumi and Emori, 2004). MaxEnt v. 3.3.3k was used to predict the potential distribution (Phillips and Dudík, 2008) with ten crossvalidate replicated runs. Jackknife analyses were performed using default parameters $(0.00001$ convergence threshold, and 500 maximum iterations). Model performance was evaluated using the area under the Receiving Operator Curve (AUC), implying excellent if greater than 0.9 . 
Based on classification of habitat suitability (Qin et al., 2017) and the IPCC Fifth Assessment Report (Mastrandrea et al., 2010), four classes of potential habitats were estimated. Optimum growing area of $A$. gigantea was determined as suitable habitat (0.5-0.8) and highly suitable habitat (0.8-1).

\section{Outlier detection}

DFDIST and BAYESCAN v.2.0 were used to identify candidate loci under natural selection (Antao and Beaumont, 2011; Foll and Gaggiotti, 2008). In DFDIST, we detected outliers through comparing observed distribution with neutral expectations at a $99.5 \%$ confidence interval (CI) with 50000 simulations. In BAYESCAN, a reversible-jump Markov chain Monte Carlo algorithm based on a Bayesian likelihood approach was used to estimate the ratio of posterior probabilities of selection over neutrality [the posterior odds (PO)]. Its parameters included 10 pilot runs of 5000 iterations followed by a burn-in of 50000 iterations, and a sample size of 5000 with a thinning interval of 20. Only loci with $\log (\mathrm{PO})>0.5$ (Bayesian factor BF $>10$ ) was considered to have substantial evidence for selection.

To ensure the accuracy of the results (Pérez-Figueroa et al., 2010), we further used Sam $\beta$ ada (Stucki et al., 2017) to detect the correlation between outliers and 22 environment variables, including three geographical variables (longitude, latitude, and altitude) and 19 environmental variables (19 bioclimatic variables from WorldClim). Based on Wald and G, significant was acquired through comparing between models with and without environmental variables with an FDR cutoff of 0.01. In addition, linear regression with one variable model in SAM was also used to analyze association of outliers with geographical and environmental variables.

\section{Results}

\section{Population genetic analyses}

We detected 136 loci in four populations of A. gigantea, 116 of which were polymorphic. The percentage of polymorphic loci was $85.29 \%$ with variation from $73.53 \%$ in DL to $80.15 \%$ in JF (mean PPL $=76.84 \%$; Table 2). The effective number of alleles, Shannon's information index and expected heterozygosity were $1.627,0.486$ and 0.340 , respectively (Table 2).

Two genetic groups were identified by Bayesian clustering analysis implemented in STRUCTURE. As shown in Figure 2, the best $\mathrm{K}$ was determined as 2 based on the highest $\Delta \mathrm{K}$ value (33.95). WZ, JF and BW populations were clustered into one group, while DL population formed another.

Table 2. Locality information and population genetic parameters of the four population of $A$. gigantea

\begin{tabular}{|c|c|c|c|c|c|c|c|c|c|c|c|}
\hline ID & Locality & Longitude & Latitude & $\begin{array}{l}\text { Altitude } \\
(\mathrm{m})\end{array}$ & $\mathrm{N}$ & $\mathrm{Na}$ & $\mathrm{Ne}$ & I & $\mathrm{He}$ & $\mathrm{UHe}$ & PPL \\
\hline DL & $\begin{array}{l}\text { Diaoluosha } \\
\text { n, Hainan }\end{array}$ & E10950' & N1840' & $425-470$ & 33 & 1.735 & 1.615 & 0.469 & 0.329 & 0.334 & $73.53 \%$ \\
\hline WZ & $\begin{array}{c}\text { Wuzhishan, } \\
\text { Hainan }\end{array}$ & E10954' & N18 $54^{\prime}$ & 705-785 & 33 & 1.779 & 1.621 & 0.488 & 0.340 & 0.345 & $77.94 \%$ \\
\hline $\mathrm{JF}$ & $\begin{array}{c}\text { Jianfengling, } \\
\text { Hainan }\end{array}$ & E108 $52^{\prime}$ & N1844' & $806-926$ & 28 & 1.801 & 1.662 & 0.511 & 0.358 & 0.364 & $80.15 \%$ \\
\hline BW & $\begin{array}{c}\text { Bawangling, } \\
\text { Hainan }\end{array}$ & $\mathrm{E} 109^{\circ} 11^{\prime}$ & $\mathrm{N} 19^{\circ} 05^{\prime}$ & $\begin{array}{l}919- \\
1024\end{array}$ & 23 & 1.757 & 1.611 & 0.476 & 0.332 & 0.340 & $75.74 \%$ \\
\hline \multicolumn{4}{|c|}{ Total average } & & 1 & 1.768 & 1.627 & 0.486 & 0.340 & 0.346 & $76.84 \%$ \\
\hline \multicolumn{4}{|c|}{ Species level } & & 117 & 1.853 & 1.718 & 0.548 & 0.385 & 0.387 & $85.29 \%$ \\
\hline
\end{tabular}

$\mathrm{N}$ : the sample size for each population; Na: the actual number of alleles; Ne: the effective number of alleles; I: the Shannon's Information Index; He: the expected heterozygosity; UHe: the unbiased expected heterozygosity; PPL: the percentage of polymorphic loci. 
a

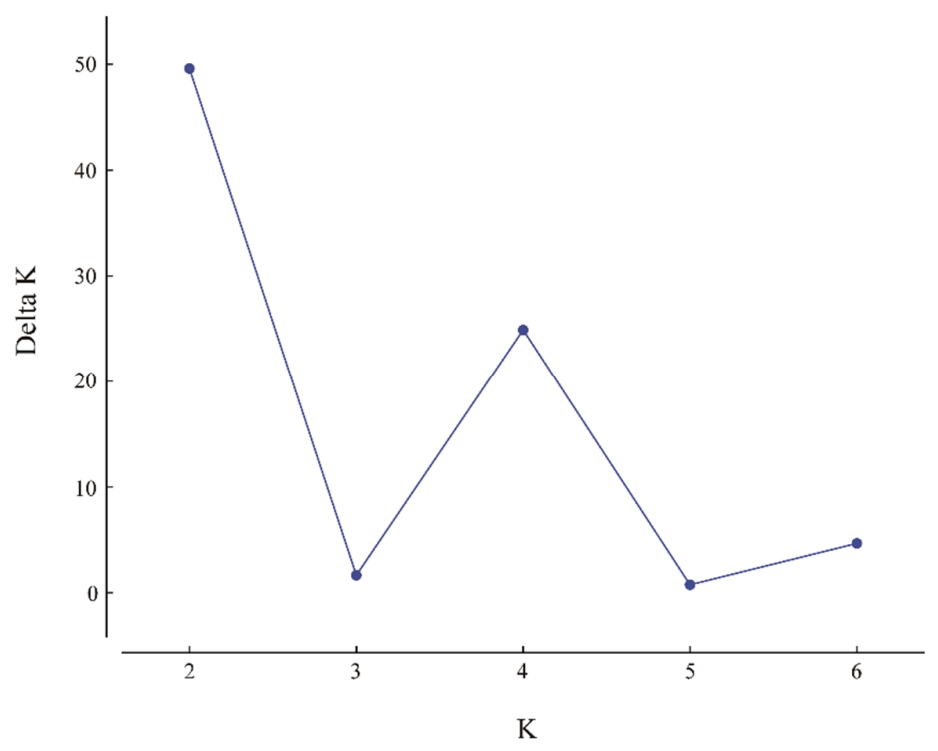

b

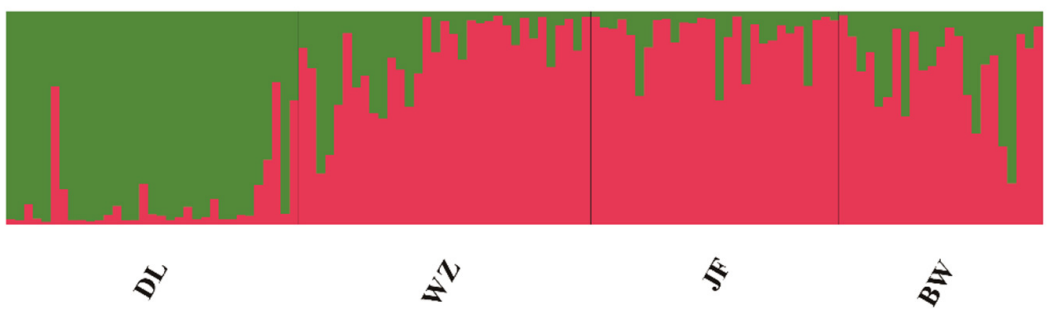

Figure 2. Genetic structure was detected using STRUCTURE based on Bayesian clustering

(a) Estimates of the posterior probability of the data for a given $\mathrm{K}$. (b) Individual assignments for clustering scenarios of $\mathrm{K}=2$.

AMOVA analysis showed that the two STRUCTURE-based groups had a low genetic differentiation $($ Fst $=0.0801, \mathrm{P}<0.005$; Table 3). Genetic variations mainly occurred within populations (91.99\%, Table 3). Similar to AMOVA, HICKORY $\theta I I$ also indicated low genetic differentiation. Full model was chosen due to the smallest DIC value $(\theta \mathrm{II}=0.0899175$; CI: $0.0733515-0.108223)$. Gene flow among populations was estimated as 4.886. Nei's genetic identity ranged from 0.9210 to 0.9354 , with an average of 0.9298 (Table 4). JF and BW populations had the largest Nei's genetic identity, whereas the smallest was between DL and JF. Mantel test showed that there was no significant correlation between genetic and geographical distance $(\mathrm{r}=0.454, \mathrm{p}=0.17)$.

By using TASSEL, 136 linked-loci produced 11 of 9180 comparison pairs (0.12\%). And linkage disequilibrium (LD) was detected with 22 of 136 loci (16.18\%; 2 > 0.1, $\mathrm{p}<0.05$; Table 5). 
Wang T et al. (2021). Not Bot Horti Agrobo 49(3):12407

Table 3. Percentage of variation in the four population of $A$. gigantea based on AMOVA analysis

\begin{tabular}{|l|c|c|c|c|c|}
\hline \multicolumn{1}{|c|}{ Source of variation } & d.f. & $\begin{array}{c}\text { Variance } \\
\text { components }\end{array}$ & Percentage of variation & F statistics & $\mathrm{p}$ \\
\hline Among groups & 1 & 0.23958 & 1.02 & Fct $=0.01018$ & 0.17129 \\
\hline Among populations within groups & 2 & 1.64549 & 6.99 & Fsc $=0.07063$ & 0.00000 \\
\hline Within populations & 113 & 21.65230 & 91.99 & Fst $=0.08009$ & 0.00000 \\
\hline
\end{tabular}

Table 4. Nei's genetic identity (above diagonal) and genetic distance (below diagonal)

\begin{tabular}{|l|c|c|c|c|}
\hline \multicolumn{1}{|c|}{ Pop } & DL & WZ & JF & BW \\
\hline DL & ${ }^{* * * *}$ & 0.9324 & 0.9210 & 0.9229 \\
\hline WZ & 0.0700 & ${ }^{* * * *}$ & 0.9323 & 0.9349 \\
\hline JF & 0.0823 & 0.0701 & ${ }^{* * * *}$ & 0.9354 \\
\hline BW & 0.0802 & 0.0673 & 0.0667 & ${ }^{* * * *}$ \\
\hline
\end{tabular}

Table 5. Linkage disequilibrium analysis among 136 ISSR loci

\begin{tabular}{|l|c|c|c|}
\hline \multicolumn{1}{|c|}{ Locus } & $\mathrm{r} 2$ & $\mathrm{D}$ & $\mathrm{p}$ \\
\hline 56 and 19 & 0.104642 & 0.429268 & 0.00052394 \\
\hline 61 and 29 & 0.126407 & 0.610433 & 0.000176258 \\
\hline 72 and 60 & 0.129396 & 0.366359 & 0.000149455 \\
\hline 74 and 48 & 0.101802 & 0.413194 & 0.000679577 \\
\hline 77 and 76 & 0.250007 & 0.526611 & 0.000000087 \\
\hline 88 and 67 & 0.102451 & 0.329688 & 0.001792001 \\
\hline 100 and 27 & 0.108750 & 0.394679 & 0.000448761 \\
\hline 108 and 107 & 0.111852 & 0.460829 & 0.001380078 \\
\hline 111 and 101 & 0.117718 & 0.35 & 0.000439826 \\
\hline 112 and 69 & 0.126999 & 0.385093 & 0.000376822 \\
\hline 122 and 23 & 0.101011 & 0.468182 & 0.000813120 \\
\hline
\end{tabular}

\section{Spatial genetic autocorrelation analysis}

No significant spatial autocorrelation was found at large scale among the four populations due to the lack of significance in mean Moran's I (Figure 3). By contrast, a significant positive Fij value was detected in the smallest distance interval $(\mathrm{d} \leq 0.2 \mathrm{~km})$. Fij values were negative in other distance intervals with no significant correlation. The Sp statistics for $A$. gigantea was 0.0014 (Table 6; Figure 4).

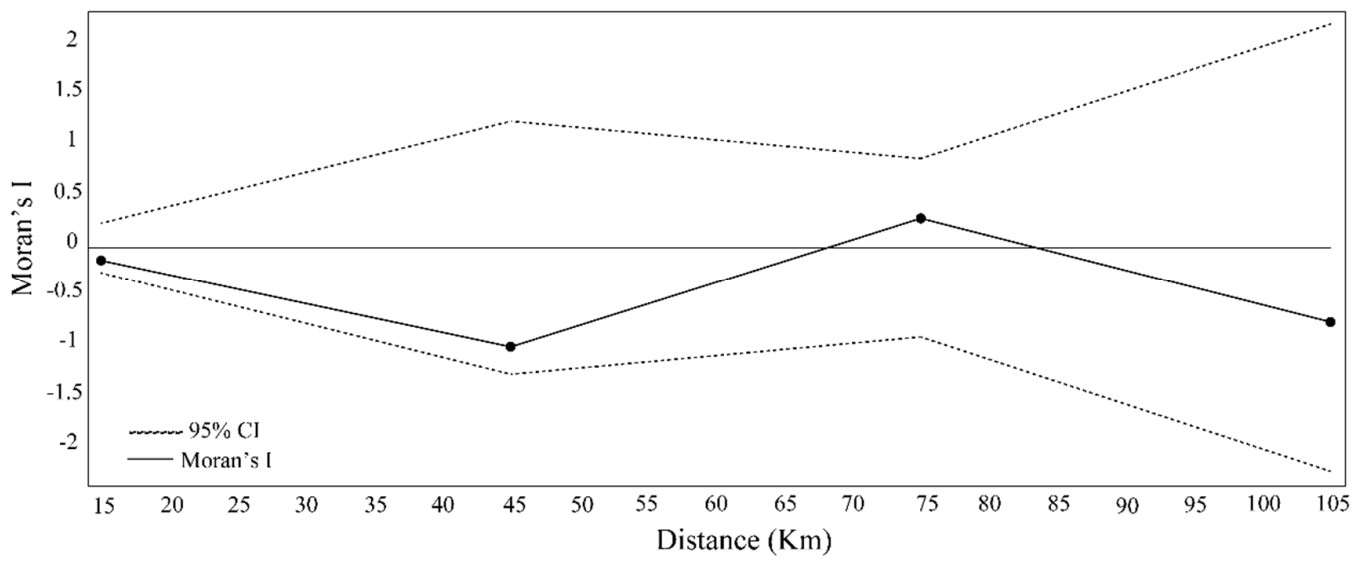

Figure 3. Spatial autocorrelation analysis in large-scale among four population of $A$. gigantea using SAM 


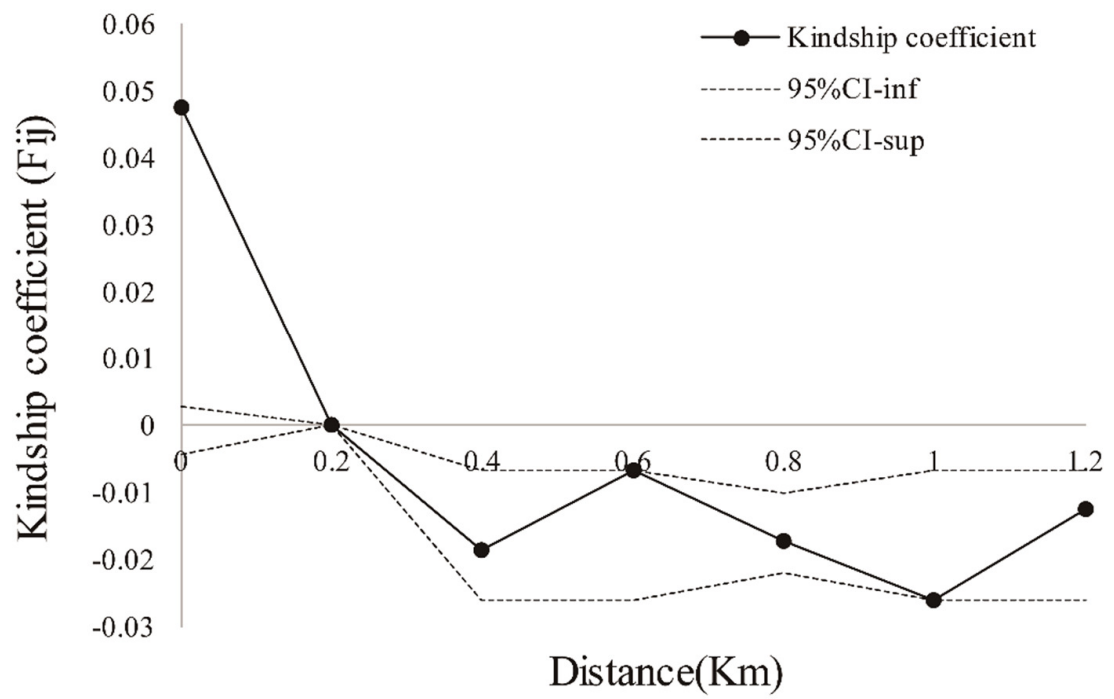

Figure 4. Fine-scale spatial autocorrelation analysis among four population of $A$. gigantea implemented in SPAGeDi

Table 6. Fine-scale spatial genetic structure (FSGS) among different population combinations

\begin{tabular}{|c|c|c|c|c|c|c|c|c|c|}
\hline Group & Fis & F1 & $\mathrm{p}$ & b-log & $\mathrm{p}$ & Sp & Sp-avg & Avg_T & Avg_P \\
\hline \multirow{2}{*}{ Group1: DL+WZ+JF } & 0.95 & 0.0524 & 0 & 0.0019 & 0.8179 & -0.0020 & \multirow{2}{*}{-0.0017} & \multirow{2}{*}{23.16} & \multirow{2}{*}{1549.67} \\
\hline & 0 & 0.0339 & 0 & 0.0013 & 0.8168 & -0.0013 & & & \\
\hline \multirow{2}{*}{ Group2: $\mathrm{WZ}+\mathrm{BW}+\mathrm{JF}$} & 0.95 & 0.0461 & 0 & -0.0098 & 0.4922 & 0.0103 & \multirow{2}{*}{0.0085} & \multirow{2}{*}{21.85} & \multirow{2}{*}{1565.67} \\
\hline & 0 & 0.0292 & 0 & -0.0066 & 0.4979 & 0.0068 & & & \\
\hline \multirow{2}{*}{ Group3: DL+BW+JF } & 0.95 & 0.0551 & 0 & -0.0327 & 0.1696 & 0.0346 & \multirow{2}{*}{0.0288} & \multirow{2}{*}{21.94} & \multirow{2}{*}{1542} \\
\hline & 0 & 0.0355 & 0 & -0.0222 & 0.1608 & 0.0231 & & & \\
\hline \multirow{2}{*}{ Group4: DL+WZ+BW } & 0.95 & 0.0521 & 0 & 0.0055 & 0.4985 & -0.0058 & \multirow{2}{*}{-0.0048} & \multirow{2}{*}{22.82} & \multirow{2}{*}{1582.67} \\
\hline & 0 & 0.0334 & 0 & 0.0037 & 0.5036 & -0.0038 & & & \\
\hline \multirow{2}{*}{$\mathrm{DL}+\mathrm{WZ}+\mathrm{JF}+\mathrm{BW}$} & 0.95 & 0.0577 & 0 & -0.0016 & 0.8863 & 0.0017 & \multirow{2}{*}{0.0014} & \multirow{2}{*}{22.44} & \multirow{2}{*}{1560} \\
\hline & 0 & 0.0378 & 0 & -0.0011 & 0.8796 & 0.0011 & & & \\
\hline
\end{tabular}

b-log: slop of the regression of kinship with the logarithm of the distance; F1: mean Fij of the first distance interval; Sp-avg: average value of $\mathrm{sp}$ when fis is 0 and 0. 95; Avg_T: annual mean temperature of different population combinations; Avg_P: average annual precipitation of different population combinations

\section{Effects of environmental factors on genetic diversity and FSGS}

Based on Pearson correlation analysis, four genetic parameters ( $\mathrm{Ne}, \mathrm{I}, \mathrm{He}$, and $\mathrm{UHe}$ ) exhibited a significant negative correlation with three environmental variables (bio2, bio3, and bio18; Table 8). The best linear model correlated FSGS with annual precipitation (Avg_P) and with group one (DL+WZ+JF) excluded (Adj.R2=0.9987, p=0.0161; Table 6; Table 7: Model D). Of note, Avg_P exerted a significant negative effect on FSGS. However, when both Avg_T and Avg_P or only Avg_T was considered, only a nonsignificant negative effect was detected. 
Table 7. Best linear model correlating climatic factors and FSGS, as identified by AIC, after stepwise selection

\begin{tabular}{|l|c|c|c|c|}
\hline \multirow{2}{*}{ Model } & \multicolumn{2}{|c|}{ Variable estimates } & \multirow{2}{*}{ Adj.R2 } & \multirow{2}{*}{$\mathrm{p}$} \\
\cline { 2 - 3 } & Avg_T & Avg_P & & 0.3448 \\
\hline A & -0.0201 & -0.0190 & 0.6434 & 0.2361 \\
\hline B & -0.0234 & $/$ & 0.3754 & 0.3162 \\
\hline C & $/$ & -0.0234 & 0.2013 & 0.0161 \\
\hline
\end{tabular}

A: complete model based on both variables; B: model without Avg_P; C: model without Avg_T; D: model without Avg_T and with outlier group1 (DL+WZ+JF) removed

Table 8. Correlation between genetic parameters and environmental variables based on Pearson correlation analysis

\begin{tabular}{|l|c|}
\hline \multicolumn{1}{|c|}{ Genetic parameters } & Environmental variables \\
\hline $\mathrm{Ne}$ & Bio2 $(\mathrm{r}=-0.987 ; \mathrm{p}=0.013)$ \\
\hline $\mathrm{I}$ & Bio18 $(\mathrm{r}=-0.984 ; \mathrm{p}=0.016)$ \\
\hline $\mathrm{He}$ & Bio18 $(\mathrm{r}=-0.981 ; \mathrm{p}=0.019)$ \\
\hline $\mathrm{UHe}$ & Bio3 $(\mathrm{r}=-0.963 ; \mathrm{p}=0.037) ;$ Bio18 $(\mathrm{r}=-0.996 ; \mathrm{p}=0.004)$ \\
\hline
\end{tabular}

\section{Predicting the potential distribution of A. gigantea}

The Maxent model for A. gigantea performed well with AUC 0.962. Precipitation of driest month (bio14, 23.4\%) contributed most to the model, followed by mean temperature of coldest quarter (bio11, $22.4 \%$ ), precipitation of driest quarter (bio17, 16.4\%), temperature annual range (bio5-bio6) (bio7, 9.7\%) in temperature of coldest month (bio6, 8.2\%) and isothermality (bio2/bio7) $\left({ }^{*} 100\right)($ bio3, 7.4\%). The cumulative contribution of these six factors was $87.5 \%$ (Table 9).

Table 9. Environmental variables used in the study and their percentage contribution

\begin{tabular}{|l|c|c|}
\hline \multicolumn{1}{|c|}{ Code } & Environmental variables & \% Contribution \\
\hline bio14 & Precipitation of Driest Month & 23.4 \\
\hline bio11 & Mean Temperature of Coldest Quarter & 22.4 \\
\hline bio17 & Precipitation of Driest Quarter & 16.4 \\
\hline bio7 & Temperature Annual Range (BIO5-BIO6) & 8.7 \\
\hline bio6 & Min Temperature of Coldest Month & 7.4 \\
\hline bio3 & Isothermality (BIO2/BIO7) $\left.{ }^{*} 100\right)$ & 4.1 \\
\hline bio1 & Annual Mean Temperature & 3 \\
\hline bio2 & Mean Diurnal Range (Mean of monthly (max temp - min & 1.8 \\
\hline bio15 & Precipitation Seasonality (Coefficient of Variation) & 1.2 \\
\hline bio4 & Temperature Seasonality (standard deviation $\left.{ }^{*} 100\right)$ & 0.6 \\
\hline bio12 & Annual Precipitation & 0.4 \\
\hline bio13 & Precipitation of Wettest Month & 0.4 \\
\hline bio10 & Mean Temperature of Warmest Quarter & 0.4 \\
\hline bio18 & Precipitation of Warmest Quarter & 0.2 \\
\hline bio8 & Mean Temperature of Wettest Quarter & 0.1 \\
\hline bio9 & Mean Temperature of Driest Quarter & 0.1 \\
\hline bio16 & Precipitation of Wettest Quarter & 0.1 \\
\hline bio19 & Precipitation of Coldest Quarter & 0 \\
\hline bio5 & Max Temperature of Warmest Month & \\
\hline
\end{tabular}


We predicted the future, current, and historical distribution for A. gigantea (Figure 5). The current distribution prediction was basically consistent with the actual distribution, including southern Yunnan, southwestern Guangxi, southern Guangdong, Hainan, and Taiwan. Future habitats were predicted to concentrate in central Guangxi and a small region of western Guangdong and Hainan, with a tendency to expand into Tibet.

Based on MIROC model, the distribution of $A$. gigantea during HOL (69.51\%) and LGM (96.08\%) was similar to current distribution except slight contraction and more stable, respectively, whereas distribution in LGM was severely limited to a few parts of southeastern Yunnan and Tibet based on CCSM model (2.83\%). In LIG (11.08\%), suitable habitats of $A$. gigantea were found concentrated in Hainan. In comparison to LIG, models CCSM and MIROC produced very different distributions for LGM. The former predicted a significant narrow distribution (25.53\%), whereas the latter projected a much wider distribution $(86.75 \%)$ (Table 10). Overall, the suitable region of $A$. gigantea showed a trend of expansion from Paleoclimate to the present, but a trend of slight contraction in the future.

Table 10. Area of distribution range of $A$. gigantea under different climate scenarios

\begin{tabular}{|l|c|c|c|c|c|c|}
\hline \multirow{2}{*}{ Class } & \multicolumn{7}{|c|}{ Area $\left(\mathrm{km}^{2}\right)$} \\
\cline { 2 - 7 } & Future & Current & HOL & CCSM & MIROC & LIG \\
\hline $0-0.2$ & $8,260,608$ & $8,194,304$ & $8,334,208$ & $8,749,280$ & $8,273,856$ & $8,788,848$ \\
\hline $0.2-0.5$ & 445,696 & 456,000 & 380,800 & 109,056 & 386,576 & 40,352 \\
\hline $0.5-0.8$ & 134,912 & 207,440 & 141,712 & 6,000 & 197,056 & 22,928 \\
\hline $0.8-1$ & 11,200 & 4,784 & 5,808 & 0 & 6,848 & 576 \\
\hline $0.5-1$ & 146,112 & 212,224 & 147,520 & 6,000 & 203,904 & 23,504 \\
\hline${ }^{*}$ AOC & $68.85 \%$ & $/$ & $69.51 \%$ & $2.83 \%$ & $96.08 \%$ & $11.08 \%$ \\
\hline${ }^{*}$ AOL & $621.6 \%$ & $902.9 \%$ & $627.6 \%$ & $25.53 \%$ & $867.5 \%$ & $/$ \\
\hline
\end{tabular}

*AOC: area of 0.5-1 class distribution range of each climate scenarios/ area of 0.5-1 class distribution range of current;

${ }^{*} \mathrm{AOL}$ : area of 0.5-1 class distribution range of each climate scenarios/ area of 0.5-1 class distribution range of LIG

\section{Loci under selection}

DFDIST and BAYESCAN detected two (loci 18 and 62, Figure 6a) and one (loci 89, Figure 6b) outliers, respectively. However, no outlier was identified using Sambada. Linear regression with one variable model in SAM showed that loci 18 and 62 were positively and negatively correlated with six environmental variables (latitude, bio2, bio7, bio12, bio13, and bio16), respectively (Table 11). Loci 89 was positively correlated with nine environmental variables (longitude, bio1, bio3, bio5, bio6, bio8, bio9, bio10, and bio11) and negatively correlated with three environmental variables (altitude, bio4, and bio15) (Table 11). 


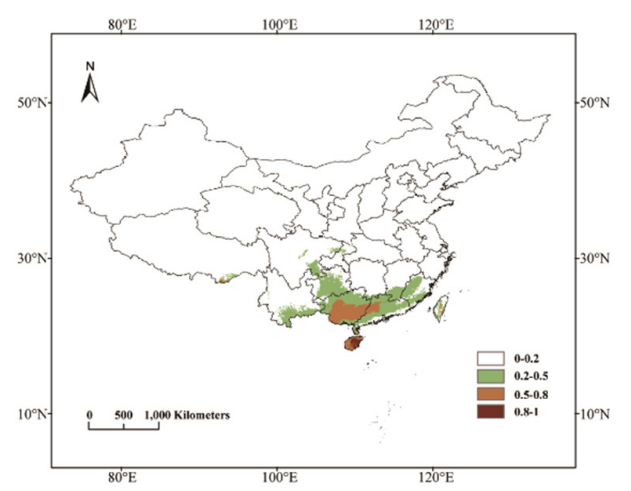

$\mathrm{c}$

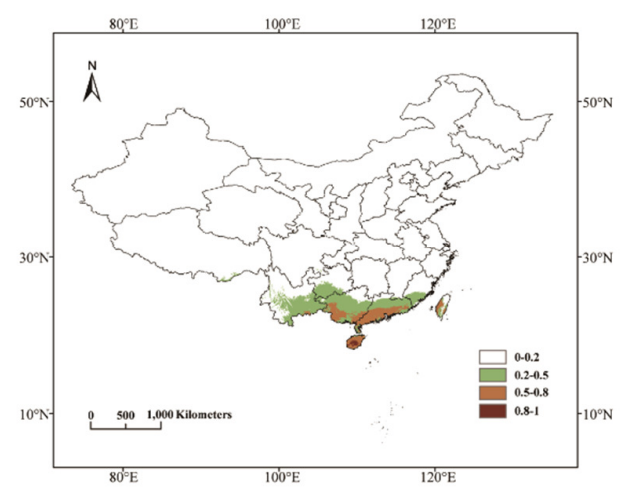

e

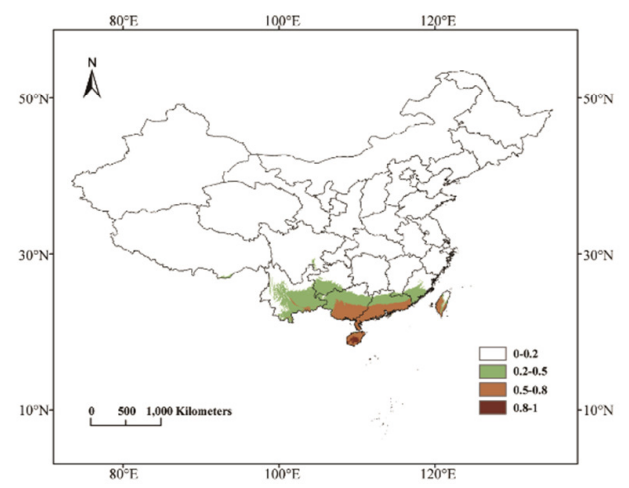

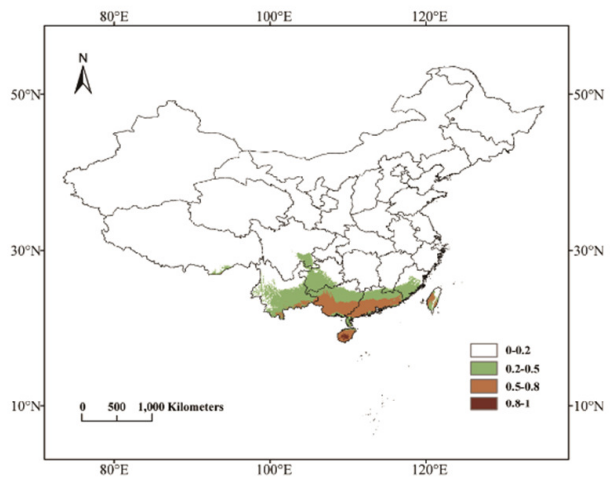

d

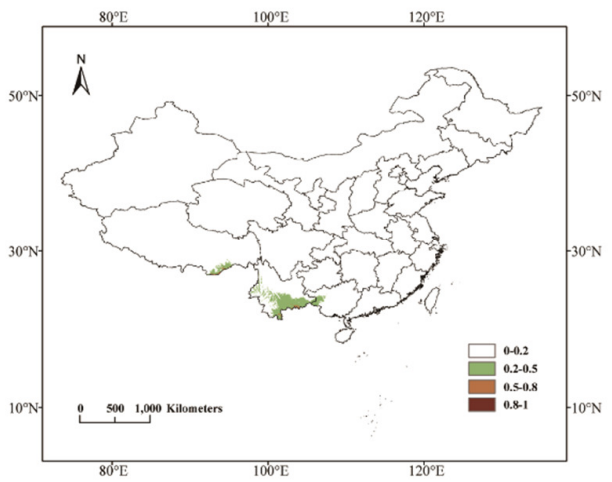

f

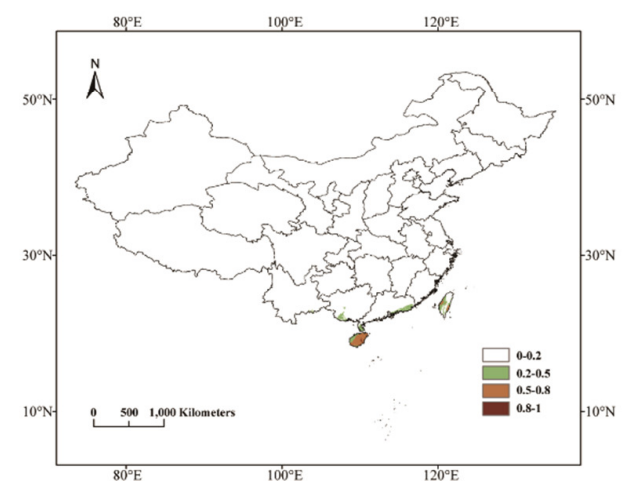

Figure 5. Predicted future, current and historical period habitat for $A$. gigantea

(a) Future suitable habitats (2070, average of predictions for 2061-2080); (b) Current suitable habitats; (c) Holocene (HOL); (d) Paleoclimate predictions from CCSM 4 climatic model for the last glacial maximum (LGM, 25-17 ka BP); (e) Paleoclimate predictions from MIROC climatic model for the last glacial maximum (LGM); (f) Paleoclimate (LIG, the last interglacial period, $130-115 \mathrm{ka} \mathrm{BP}$ ) predictions. 
a

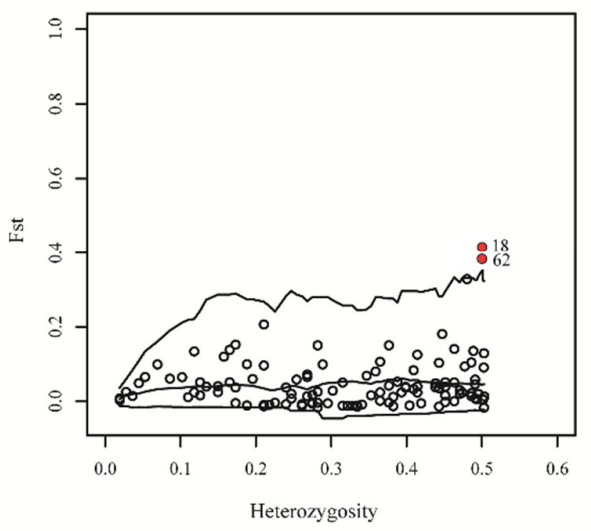

b

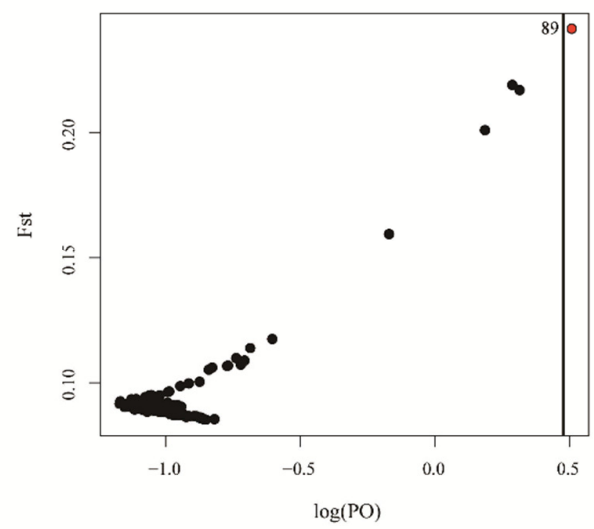

Figure 6. Outlier loci identified by DFDIST and BAYESCAN. (a) Outlier detection performed with DFDIST

The $0.5 \%, 50 \%$, and $99.5 \%$ represented confidence intervals, respectively. Solid red dots above the $99.5 \%$ line were identified as outlier loci. (b) Plot of Fst values and $\log$ PO for 136 loci identified using BAYESCAN. Lines with $\log$ $\mathrm{PO}=0.5$ indicate "Substantial" evidence for selection corresponding to a posterior probability of 0.99 . Solid red dots greater than $\log$ PO 0.5 represented outlier loci.

Table 11. Summary of outliers under selection identified based on genome scan methods (DFDIST and BAYESCAN), and their association with environmental variables based on the linear regression with one variable model

\begin{tabular}{|c|c|c|c|c|}
\hline Method & Loci & Variable & Slope & r2 \\
\hline \multirow{6}{*}{ DFDIST } & \multirow{6}{*}{18} & Latitude & 1.774 & 0.789 \\
\hline & & bio2 & 0.483 & 0.538 \\
\hline & & bio7 & 0.431 & 0.82 \\
\hline & & bio12 & 0.006 & 0.877 \\
\hline & & bio13 & 0.101 & 0.94 \\
\hline & & bio16 & 0.028 & 0.949 \\
\hline \multirow{6}{*}{ DFDIST } & \multirow{6}{*}{62} & Latitude & -1.595 & 0.677 \\
\hline & & bio2 & -0.585 & 0.838 \\
\hline & & bio7 & -0.455 & 0.972 \\
\hline & & bio12 & -0.006 & 0.897 \\
\hline & & bio13 & -0.093 & 0.841 \\
\hline & & bio16 & -0.027 & 0.922 \\
\hline \multirow{12}{*}{ BAYESCAN } & \multirow{12}{*}{89} & longitude & 0.722 & 0.972 \\
\hline & & altitude & -0.001 & 0.642 \\
\hline & & biol & 0.18 & 0.898 \\
\hline & & bio3 & 0.156 & 0.657 \\
\hline & & bio4 & -0.021 & 0.57 \\
\hline & & bio5 & 0.185 & 0.978 \\
\hline & & bio6 & 0.15 & 0.75 \\
\hline & & bio8 & 0.245 & 0.983 \\
\hline & & bio9 & 0.132 & 0.91 \\
\hline & & bio10 & 0.19 & 0.912 \\
\hline & & biol1 & 0.163 & 0.875 \\
\hline & & bio15 & -0.16 & 0.74 \\
\hline
\end{tabular}




\section{Discussion}

In this study, we first estimated and reported in genetic diversity of four $A$. gigantea populations in Hainan Island. The result found that $A$. gigantea had high genetic diversity based on Shannon's information index $(\mathrm{I}=0.548)$, expected heterozygosity $(\mathrm{He}=0.385)$ and percentage of polymorphic loci ( $\mathrm{PPL}=85.29 \%)$. Especially, expected heterozygosity and percentage of polymorphic loci were much higher than homosporous ferns (mean species-level estimates; PPL $=36.1 \%, \mathrm{He}=0.132 ; \mathrm{Li}$ and Haufler, 1999). This result was similar to SSR analysis in $A$. gigantea (Ruan et al., 2017). In addition, high genetic identity was found in pairwise populations of $A$.gigantea. The same phenomenon also occurs in four tropical Adiantum species based on ISSR marker (Korpelainen et al., 2005).

Generally, island populations have lower genetic variation compared to their mainland counterparts due to founder effect (Frankham, 1997; Su et al., 2010). Contrary to expectations, A. gigantea exhibited high genetic diversity in Hainan Island. On the one hand, we need to further survey and compare genetic variation of $A$. gigantea in mainland populations. On the other hand, $A$. gigantea still possibly maintains the previous high genetic variation as a long-lived relict tree fern. In addition, Neogene multiple connections between Hainan Island and Chinese mainland during the late Pleistocene-early Holocene period (Hope, 2005; Yan, 2006) have transformed more genetic variation from mainland population into island populations (Kolbe et al., 2004).

The plant mating system is a key factor influencing the genetic diversity (Huang et al., 2019). Homosporous fern with only one type of spore to form a bisexual gametophyte possesses three modes of sexual reproduction: intragametophytic selfing, intergametophytic selfing, and intergametophytic crossing (Wang et al., 2012). Tree ferns are generally supposed to be outcrossing like A. firma, Cyathea stipularis and Lophosoria quadripinnata (Soltis et al., 1991). Cyatheaceae species are especially intergametophytic mating (Chen, 1995; Chiou et al., 2000, 2003), which are further confirmed based on ISSR investigations on A. spinulosa, showing that sexual recombination is the predominant source of genetic variation (Wang et al., 2012). Although there is currently no report on the breeding mode of $A$. gigantea, we infer that it is outcrossing as a member of Cyatheaceae, which can promote population genetic variation. Except for sexual reproduction, some ferns also have vegetative propagation (Mcveigh, 1937; White, 1969; Johns and Edwards, 1991). As for A. spinulosa, most of natural populations are dominated by asexual reproduction, but there are some reproducing primarily by sexual reproduction (Wang et al., 2012). Of note, somatic mutations may generate a considerable amount of genetic variation for clonal lineages (Wang et al., 2012). Clonal growth is also indeed observed in other tree ferns such as A. firma (Mehltreter and García-Franco, 2008; Lehnert, 2011; Santiago and Luis, 2014). Hence, high genetic diversity of $A$. gigantea was possibly ascribed to sexual reproduction, and clonal growth with somatic mutations. Furthermore, the identified linkage disequilibrium can result in the fixation of different multilocus genotypes within populations to increase genetic variation (Jiménez et al., 2010; Loveless and Hamrick, 1984). High genetic identity among four populations was possibly ascribed to the continuous presence of $A$. gigantea in Hainan islands in the past except high level of gene flow because island-like mountains originated from the upliftment of Hainan Island (Zhang and Liu, 1989) or the Quaternary transgression (Shi et al., 2006).

The spatial genetic autocorrelation was also investigated in the four $A$. gigantea populations in Hainan Island. As expected, $A$. gigantea had a weak SGS in fine scale and lacked spatial autocorrelation in large scale among populations. The SGS was different among populations. SGS among DL, JF and BW (Spg3 = 0.0288) was stronger than that among WZ, JF and BW $(\mathrm{Spg} 2=0.0085)$ and among the four populations (Spall_pop $=0.0014)$. This SGS result was contrary to the other tree fern like $A$. firma with strong SGS between two populations (Santiago and Luis, 2014). The reason might be attributed to factors other than life history and breeding system because all tree ferns have similar life form and outcrossing mode (Soltis et al., 1991). 
Compared to breeding system, spore dispersal ability has a deeper influence on the spatial genetic structure of fern population (Jiménez et al., 2010; Pryor et al., 2001). Ferns can produce a large amount of small and light spores (c. 0.02-0.13 mm; Knobloch, 1969; Makgomol, 2006), which plays an important role (Li et al., 2010). The windborne spores usually have a high dispersal potential $(500-800 \mathrm{~km})$ and even up to 3,200 $\mathrm{km}$ (Tryon, 1970, 1972), which could span island-like habitat and complicated mountains system with deep and wide valley in Hainan Island leading to lack of spatial genetic structure. Although spores of $A$. gigantea lost viability quickly at room temperature ( $\mathrm{Li}$ et al., 2010), abundant rainfall in tropical habitats between May and October ensures their rapid germination and move requirement of spermatozoids for water, especially in June when spores mature (Peck et al., 1990; Haufler et al., 2000; Korpelainen et al., 2005). Unique tropical humid climate in Hainan Island may promote the spread of fern spores and decreases population differentiation (Fst $=0.0758)$ through monsoon and rainy season with storm and typhoon (Wang et al., 2016). Lack of pattern of isolation by distance further justified the spatial genetic structure feature of $A$. gigantea. In this study, a negative correlation was detected between the annual precipitation and the strength of SGS quantified by the $S p$ value. Hence, the clonality, dispersal, and tropical climate may exert an overarching effect on SGS of $A$. gigantea. Compared to selfing plants, outcrossing plants generally tend to present a weaker SGS (Vekemans and Hardy, 2004). Moreover, the lack of genetic structure with high gene flow in A. gigantea populations implied that habitat was suitable for spore germination and gametophyte development and the effective mixing of different genotypes from spore dispersal (Jiménez et al., 2010). The similar result was detected in A. spinulosa populations in Hainan Island (Su et al., 2004). Of note, weaker SGS of $A$. gigantea occurred in the smallest distance interval $(\mathrm{d} \leq 0.2 \mathrm{~km})$. This was possibly related to the formation of localized spore shadows around colonizing sporophytes (Chung and Chung, 2013) and some spores falling near the parent plants (Chung and Chung, 2013; Peck et al., 1990; Dyer, 1994). Compared to co-dominant markers such as microsatellites, dominant makers may reveal FSGS with more accuracy by avoiding null alleles (Chung and Chung, 2013). It has been noted that AFLP-based $\mathrm{Sp}$ values are significantly higher than those from microsatellites (GelmiCandusso et al., 2017; Jump et al., 2012).

Natural selection can drive the formation of fine spatial genetic structure through local adaptation to environment (Lehnert et al., 2019). In this study, we detected three outliers by DFDIST and BAYESCAN, which showed that $A$. gigantea had very strong adaptability to environment. Environmental factors, especially climatic conditions such as temperature and precipitation, have profound effect on the distribution of $A$. gigantea. Jacknife analysis indicated that temperature (47.7\%) contributed most to A. gigantea distribution, followed by precipitation (39.8\%). Annual precipitation and temperature also separately exerted on a significant negative effect on FSGS of $A$. gigantea. Hence, the two climatic factors might facilitate fine-scale genetic divergence between populations, where there were subtle differences in annual precipitation and temperature. Weak FSGS also showed that genotypes related to adaptation are limited to a small area, and not randomly distributed (Torres et al., 2019).

Population density is also among the factors affecting spatial genetic structure (Zhang et al., 2019). A reduced overlap of seed shadows can increase SGS in low density populations (Torroba-Balmori et al., 2017; Vekemans and Hardy, 2004; Hamrick and Trapnell, 2011). Limited seed dispersal and the number and location of mature trees also affect the level and pattern of SGS (Hamrick and Trapnell, 2011). Generally, SGS in plants is the strongest at the least disturbed site with the lowest adult density (Gonzales et al., 2010; Hamrick and Trapnell, 2011). In this study, four populations were from Hainan Island tropical mountain cloud forests (> $1200 \mathrm{~m}$ ) including Wuzhishan, Bawangling, Jianfengling, and Diaoluoshan (Wang et al., 2016), which was possibly the consequence of the island-like fragmentation of cloud forests from past connectivity (RamírezBarahona and Eguiarte, 2014). The similar high population density may make their spatial genetic structure similar, resulting in lack of spatial autocorrelation.

Potential distribution of $A$. gigantea was estimated using MAXENT with good AUC value. It was found to be minimal in the last interglacial period, expansive in the last glacial maximum (MIROC model), and further shrunken in the last interglacial period and in the future, respectively. Under two palaeoclimate models 
(MIROC and CCSM), we obtained different predictions during the LGM. The same phenomenon was observed in another tree fern $A$. firma with a more stable distribution in the LGM period based on MIROC prediction rather than CCSM, which is probably closely associated with different precipitation level of the two models (Irez-Barahona and Eguiarte, 2014). It implies the importance of model selection and influence of model on prediction of past distributions of $A$. gigantea. During the LGM, climate and sea-level fluctuation during Quaternary glacial period imposed a huge impact on Hainan Island populations, although this area was not covered by ice sheets (Liu et al., 2020). Hainan Island has a warmer and more humid climate from a stronger Asian summer monsoon (Liu et al., 2020). Meanwhile, the level of precipitation became increasing with the formation of land-bridges between Hainan Island and mainland. As a result, stable habitats allowed $A$. gigantea to expand rapidly during the LGM (Liu et al., 2013). In addition, the differences between the current and past distributions suggested that $A$. gigantea probably underwent distribution changes within a relatively short period of time (Ramírez-Barahona and Eguiarte, 2014).

The first $\mathrm{x}$-intercept is considered as the genetic patch size when SGS is positive (Escudero et al., 2003; Peakall et al., 2003; Torres et al., 2019), interpretation of which should be with caution because the sampling and the distance class also affect spatial autocorrelation (Vekemans and Hardy, 2004; Torres et al., 2019). In this study, these limitations may not affect the analysis because our distance setting included all individuals and enabled to detect genetic structure.

Currently, ferns are facing serious threats due to habitat shrinkage caused by environmental changes, human disturbance, and overexploitation (Ibars and Estrelles, 2012). In this context, this study has provided valuable genetic information for $A$. gigantea conservation. With the development of tourism, human disturbance has been increasing in Hainan Island. The growth and propagation of $A$. gigantea suffer negative impacts (Dai and Zhou, 2000). Priority should be given for populations with high genetic diversity when protection measures are taken. In-situ conservation may also be considered in the natural reserve.

\section{Conclusions}

To our knowledge, it is the first to survey the spatial genetic structure and genetic diversity of $A$. gigantea populations in Hainan Island. All the four populations exhibit a high level of genetic diversity, a weak fine spatial genetic structure, and a lack of spatial autocorrelation at large scale. Factors such as long-distance spore dispersal, outcrossing system, and temperature and precipitation conditions are proposed to contribute to this phenomenon. Together with population genetic variation, the suitable precipitation and temperature may have created an adequate environment for $A$. gigantea in Hainan Island, allowing the fern to expand rapidly during the LGM. In addition, $A$. gigantea populations are found to maintain sufficient gene flows and a weak spatial genetic structure, which may be associated with its local adaptation to fluctuating environments. These findings are helpful to formulate the protection strategy of $A$. gigantea in Hainan Island.

\section{Authors' Contributions}

YS and TW proposed and designed this research. ZY and YS collected samples and conducted the experiments. XR, SL and ZW analyzed the data. YS, TW and SL wrote the manuscript, and YS, ZW and TW corrected the manuscript. All authors read and approved the final manuscript. 


\section{Acknowledgements}

This work was supported by the National Natural Science Foundation of China [31670200, 31770587, 31872670, and 32071781], Guangdong Basic and Applied Basic Research Foundation [2021A1515010911], and Project of Department of Science and Technology of Shenzhen City, Guangdong, China [JCYJ20190813172001780].

\section{Conflict of Interests}

The authors declare that there are no conflicts of interest related to this article.

\section{References}

$\mathrm{Au}$ GH (2004). Research advance in the Cyatheaceae. Journal of Neijiang Teachers College 19:79-82. http://en.cnki.com.cn/Article_en/CJFDTOTAL-NJSG200406018.htm

Bucharova A, Munzbergova Z (2012). Gene flow among populations of two rare co-occurring fern species differing in ploidy level. PLoS One 7(9):e45855. https://doi.org/10.1371/journal.pone.0045855

Chen ML (1995). The study of genetic structure of Sphaeropteris lepifera (HooK.) Tryon (Cyatheaceae) in Taiwan. M.S. thesis, Department of Biology, Natl. Taiwan Normal University.

Chiou WL, Huang YM, Lee PH (2003). Mating systems of Cyatheaceae native to Taiwan. In: Chandra S, Srivastava M (Eds). Pteridology in the new millennium. Springer, Dordrecht. https://doi.org/10.1007/978-94-017-2811$9+32$

Chiou WL, Lee PH, Ying SS (2000). Reproductive biology of gametophytes of Cyathea podophylla (Hook.) Copel. Taiwan Journal of Forest Science 15:1-12. https://doi.org/10.7075/TJFS.200003.0001

Chung MY, Chung MG (2013). Significant spatial aggregation and fine-scale genetic structure in the homosporous fern Cyrtomium falcatum (Dryopteridaceae). New Phytologist 199:663-672. https://doi.org/10.1111/nph.12293

CITES (2017). Convention on international trade in endangered species of wild fauna and flora. Appendices I, II, and III. Retrieved 2018 June 7 from https://cites.org/eng/app/appendices.php.

Dyer AF (1994). Natural soil spore banks - can they be used to retrieve lost ferns? Biodiversity and Conservation 3:160175. https://doi.org/10.1007/BF02291886

Frankham R (1997). Do island populations have less genetic variation than mainland populations? Heredity 78:311-327. https://doi.org/10.1038/hdy.1997.46

Fu LG (1992). Red List of China - rare and endangered plants. Vol. 1 (Science Press: Beijing).

Hope G (2005). The quaternary in Southeast Asia. In: Gupta A (Ed). The Physical Geography of Southeast Asia. Oxford University Press, Oxford, UK, pp 24-37. https://doi.org/10.1093/oso/9780199248025.003.0012

Huang R, Chu QH, Lu GH, Wang YQ (2019). Comparative studies on population genetic structure of two closely related selfing and outcrossing Zingiber species in Hainan Island. Scientific Reports 9:17997. https://doi.org/10.1038/s41598-019-54526-y

Jimenez A, Holderegger R, Csencsics D, Quintanilla LG (2010). Microsatellites reveal substantial among-population genetic differentiation and strong inbreeding in the relict fern Dryopteris aemula. Annals of Botany 106:149155. https://doi.org/10.1093/aob/mcq094

Johns RJ, Edwards PJ (1991). Vegetative reproduction in Pteridophytes. Curtis's Botanical Magazine 8:107-158. https://doi.org/10.1111/j.1467-8748.1991.tb00370.x

Knobloch IW (1969). The spore pattern in some species of Cheilanthes. American Journal of Botany 56:646-653. https://doi.org/10.1002/j.1537-2197.1969.tb07581.x

Kolbe JJ, Glor RE, Rodriguez-Schettino L, Chamizo-Lara A, Larson A, Losos JB (2004). Genetic variation increases during biological invasion by a Cuban lizard. Nature 431:177-181. https://doi.org/10.1038/nature02807

Lehnert M (2011). Species of Cyathea in America related to the western Pacific species C. decurrens. Phytotaxa 26:39-59. https://doi.org/10.11646/phytotaxa.26.1.6 
Lehnert SJ, Dibacco C, Van-Wyngaarden M, Jeffery NW, Ben-Lowen J, Sylvester EVA, ... Bradbury IR (2019). Fine-scale temperature-associated genetic structure between inshore and offshore populations of sea scallop (Placopecten magellanicus). Heredity 122:69-80. https://doi.org/10.11646/phytotaxa.26.1.6

Li J, Haufler CH (1999). Genetic variation, breeding systems, and patterns of diversification in Hawaiian Polypodium (Polypodiaceae). Systematic Botany 24:339-355. https://doi.org/10.2307/2419694

Li Y, Wei C, He XY, Chen W, Xu S (2019). Prediction of suitable habitat for lycophytes and ferns in northeast China: A case study on Athyrium brevifrons. Chinese Geographical Science 29(6):1011-1023. https://doi.org/10.1007/s11769-019-1085-4

Li Y, Zhang YL, Jiang CD, Wang T, Wang Q, Shi L (2010). Effect of storage temperature on spore viability and early gametophyte development of three vulnerable species of Alsophila (Cyatheaceae). Australian Journal of Botany 58: 89-96. https://doi.org/10.1071/BT09180

Liu YX, Pham HT, He ZQ, Wei C (2020). Phylogeography of the cicada Platypleura hilpa in subtropical and tropical East Asia based on mitochondrial and nuclear genes and microsatellite markers. International Journal of Biological Macromolecules 151:529-544. https://doi.org/10.1016/j.ijbiomac.2020.02.183

Loveless MD, Hamrick JL (1984). Ecological determinants of genetic structure in plant populations. Annual Review of Ecology and Systematics 15:65-95. https://doi.org/10.1146/annurev.es.15.110184.000433

Makgomol K (2006). Morphology of fern spores from Phu Phan National Park. Kasetsart Journal (Natural Science) 40:116-122. https://doi.org/10.1146/annurev.es.15.110184.000433

Manel S, Williams HC, Ormerod SJ (2001). Evaluating presence-absence models in ecology: the need to account for prevalence. Journal of Applied Ecology 38(5):921-931. https://doi.org/10.1046/j.1365-2664.2001.00647.x

Mcveigh I (1937). Vegetative reproduction of the fern sporophyte. Botanical Review 3:457-497. https://doi.org/10.1007/BF02870311

Mehltreter K, García-Franco JG (2008). Leaf phenology and trunk growth of the deciduous tree fern Alsophila firma (Baker) D.S. Conant in a lower montane Mexican forest. American Fern Journal 98:1-13. https://doi.org/10.1640/0002-8444(2008)98[1:LPATGO]2.0.CO;2

Mo Y, Shi Y (1987). Paleomagnetic study and tectonic evolution of Hainan terrane and its vicinal continental coast the late Mesozoic to Cenozoic. Journal of Nanjing University 23:521-532. http://en.cnki.com.cn/Article_en/CJFDTOTAL-NJDZ198703013.htm

Nielsen LR (2004). Molecular differentiation within and among island populations of the endemic plant Scalesia affinis (Asteraceae) from the Galápagos Islands. Heredity 93:434-442. https://doi.org/10.1038/sj.hdy.6800520

Paul A, Bhattacharjee S, Choudhury BI, Khan ML (2015). Population structure and regeneration status of Cyathea gigantea (Wallich ex Hook. f.) Holttum, a tree fern in Arunachal Pradesh, India. Journal of Forest and Environmental Science 31:164-176. https://doi.org/10.7747/JFES.2015.31.3.164

Peck JH, Peck CJ, Farrar DR (1990). Influences of life history attributes on formation of local and distant fern populations. American Fern Journal 80:126-142. https://doi.org/10.2307/1547200

Pryor KV, Young JE, Rumsey FJ, Edwards KJ, Bruford MW, Rogers HJ (2001). Diversity, genetic structure and evidence of outcrossing in British populations of the rock fern Adiantum capillus-veneris using microsatellites. Molecular Ecology 10:1881-1894. https://doi.org/10.1046/j.1365-294X.2001.01343.X

Ramírez-Barahona S, Eguiarte LE (2014). Changes in the distribution of cloud forests during the last glacial predict the patterns of genetic diversity and demographic history of the tree fern Alsophila firma (Cyatheaceae). Journal of Biogeography 41:2396-2407. https://doi.org/10.1111/jbi.12396

Ramírez-Barahona S, Eguiarte LE (2015). Spatial genetic analyses reveal strong genetic structure in two populations of the outcrossing tree fern Alsophila firma (Cyatheaceae). Botanical Journal of the Linnean Society 177:439-449. https://doi.org/10.1111/boj.12248

Saro I, Garcia-Verdugo C, Gonzalez-Perez MA, Naranjo A, Santana A, Sosa PA (2019). Genetic structure of the Canarian palm tree (Phoenix canariensis) at the island scale: does the 'island within islands' concept apply to species with high colonisation ability? Plant Biology 21:101-109. https://doi.org/10.1111/plb.12913

Shi YF, Cui ZJ, Su Z (2006). The quaternary glaciations and environmental variations in China. Shijiazhuang: Hebei Science and Technology Press.

Su YJ, Wang T, Deng F (2010). Contrasting genetic variation and differentiation on Hainan Island and the Chinese mainland populations of Dacrycarpus imbricatus (Podocarpaceae). Biochemical Systematics and Ecology 38:576-584. https://doi.org/10.1016/j.bse.2010.07.003 
Su YJ, Wang T, Deng F (2010). Population genetic variation, differentiation and bottlenecks of Dacrydium pectinatum (Podocarpaceae) in Hainan Island, China: implications for its conservation. Australian Journal of Botany 58:318-326. https://doi.org/10.1071/BT09106

Torres E, Riofrio ML, Iriondo JM (2019). Complex fine-scale spatial genetic structure in Epidendrum rhopalostele: an epiphytic orchid. Heredity 122:458-467. https://doi.org/10.1038/s41437-018-0139-1

Tryon R (1970). Development and evolution of fern floras of oceanic islands. Biotropica 2:76-84. https://doi.org/10.2307/2989765

Tryon R (1972). Endemic areas and geographic speciation in tropical American ferns. Biotropica 4:121-131. https://doi.org/10.2307/2989774

Wang T, Hong YF, Wang Z, Su YJ (2019). Characterization of the complete chloroplast genome of Alsophila gigantea (Cyatheaceae), an ornamental and CITES giant tree fern. Mitochondrial DNA Part B Resources 4(1):967-968. https://doi.org/10.1080/23802359.2019.1580162

Wang T, Su YJ, Li XY, Zhen B, Chen GP, Wang BS (2003). RAPD analysis of the genetic variation within populations of a relict tree fern, Alsophila spinulosa (Cyatheaceae). Acta Ecologica Sinica 23:1200-1206. https://doi.org/10.1023/A:1022289509702

Wang T, Su YJ, Li Y (2012). Population genetic variation in the tree fern Alsophila spinulosa (Cyatheaceae): effects of Reproductive strategy. PLoS One 7(7):e41780. https://doi.org/10.1371/journal.pone.0041780

Wang XM, Zheng X, Wu H, Zhou XJ, Kuang HH, Guo HL, ... Li W (2016). Multilocus sequence typing of clinical isolates of Burkholderia pseudomallei collected in Hainan, a tropical island of Southern China. American Journal of Tropical Medicine and Hygiene 95(4):760-764. https://doi.org/10.4269/ajtmh.16-0280

Wang XX, Long WX, Yang XB, Xiong MH, Kang Y, Huang J, ... Li SX (2016). Patterns of plant diversity within and among three tropical cloud forest communities in Hainan Island. Acta Phytoecologica Sinica 40(05):469-479. https://doi.org/10.17521/cjpe.2016.0021

White RA (1969). Vegetative reproduction in the ferns II root buds in Amphora denium. Bulletin of the Torrey Botanical Club 96:10-19. https://doi.org/10.2307/2484004

Yan JA (2006). Paleontology and ecologic environmental evolution of the Quaternary in Hainan Island. Journal of Palaeogeography 8:103-115. https://doi.org/10.1360/aps040120

Zhang JJ, Jiang F, Li GY, Qin W, Wu T, Xu F, Hou YS, Song PF, Cai ZY, Zhang TZ (2021). The four antelope species on the Qinghai-Tibet plateau face habitat loss and redistribution to higher latitudes under climate change. Ecological Indicators 123:107337. https://doi.org/10.1016/j.ecolind.2021.107337

Zhang XC, Nishida H (2013). Cyatheaceae. In: Wu ZY, Raven PH, Hong DY (Eds). Flora of China. Vol. 2-3 (Pteridophytes). Beijing: Science Press, pp 134-138. http://www.iplant.cn/foc

Zhang Z, Liu R (1989). The stage-division of quaternary volcanic rocks in Hainan Island. Chinese Journal of Geology 1:67-76. http://en.dzkx.org/article/id/geology_10352

Zhang Z, Stephan WG, Li JH, Fischer GA, Ren MX, Song XQ (2019). Pollen-mediated gene flow ensures connectivity among spatially discrete subpopulations of Phalaenopsis pulcherrima, a tropical food-deceptive orchid. BMC Plant Biology 19:597. https://doi.org/10.1186/s12870-019-2179-y

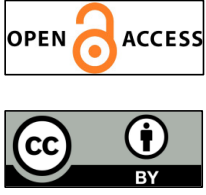

The journal offers free, immediate, and unrestricted access to peer-reviewed research and scholarly work. Users are allowed to read, download, copy, distribute, print, search, or link to the full texts of the articles, or use them for any other lawful purpose, without asking prior permission from the publisher or the author.

License - Articles published in Notulae Botanicae Horti Agrobotanici Cluj-Napoca are Open-Access, distributed under the terms and conditions of the Creative Commons Attribution (CC BY 4.0) License. (c) Articles by the authors; UASVM, Cluj-Napoca, Romania. The journal allows the author(s) to hold the copyright/to retain publishing rights without restriction. 